\title{
DIMENSÕES SÓCIO-HISTÓRICAS DA VIOLÊNCIA CONTRA A MULHER: EM PAUTA, A ORDEM DA GUERRA
}

\section{CRISTINA DOS SANTOS LOVATO ${ }^{1}$, GABRIEL DOS SANTOS KEHLER ${ }^{2}$, VANESSA SALAIBE MOTTA ${ }^{3}$}

\author{
Universidade Federal do Pampa - UNIPAMPA \\ Rua Luiz Joaquim de Sá Brito - Promorar, Itaqui - RS, 97650-000 - Brasil \\ cristinalovato@unipampa.edu.br, gabrielkehler@unipampa.edu.br, \\ vanessasalaibe23egmail.com
}

\begin{abstract}
Resumo. O presente texto se estrutura como um artigo de revisão da literatura em que se discorre sobre as dimensões sócio-históricas da violência contra a mulher. Para tal, vislumbra-se o seguinte itinerário discursivo: a) o papel do Estado na regulação da ordem da guerra, em suma, da violência; b) a retomada da discussão sobre a institucionalização do patriarcado; c) a reafirmação da posição do Feminismo enquanto dispositivo de vida e combate à violência, e, para finalizar, apresentam-se algumas considerações finais sobre a gênese e a reprodução da violência contra a mulher. Destarte, esse empreendimento corrobora com estudos prévios que destacam o modo de organização social como o alicerce em que se sustentam as prerrogativas discursivas do patriarcado que fomentam a violência contra o corpo social feminino.
\end{abstract}

Palavras-chave: Violência; Mulher; Discurso; Patriarcado; Feminismo.

\begin{abstract}
This text is structured as a literature review article in which the socio-historical dimensions of violence against women are discussed. To this end, the following discursive itinerary is envisaged: a) the role of the State in regulating the order of war, in short, violence; b) the resumption of the discussion on the institutionalization of patriarchy; c) the reaffirmation of the position of Feminism as a device for living and combating violence, and, finally, some final considerations about the genesis and reproduction of violence against women are presented. Thus, this undertaking corroborates with previous studies that highlight the mode of social organization as the foundation on which the patriarchy's discursive prerogatives that foster violence against the female social body are sustained.
\end{abstract}

Keywords: Violence; Woman; Discourse; Patriarchy; Feminism.

\footnotetext{
${ }^{1}$ Docente do curso de Bacharelado Interdisciplinar em Ciência e Tecnologia da UNIPAMPA, Campus Itaqui/RS.

${ }^{2}$ Docente do curso de Licenciatura em Matemática da UNIPAMPA, Campus Itaqui/RS.

${ }^{3}$ Bacharela em Ciência e Tecnologia pelo curso de Bacharelado Interdisciplinar em Ciência e Tecnologia da UNIPAMPA, Campus Itaqui/RS.
} 


\section{PALAVRAS INICIAIS}

O presente texto traz uma revisão de literatura sobre o fenômeno da violência contra o corpo social feminino em uma perspectiva sócio-histórica. Para tal, esse empreendimento discursivo constitui-se a partir de estudos teóricos realizados em um projeto intitulado Análise do fenômeno da violência contra o corpo social feminino nos contextos sociocultural e histórico dos municípios de Itaqui e São Borja-RS.

Neste contexto, o presente texto reproduz, em parte, o levantamento bibliográfico que fundamentou a pesquisa supracitada e amplia a discussão teórica proposta ao contextualizar a dimensão social da violência contra a mulher, em uma perspectiva histórica e cultural, contra o pano de fundo do sistema patriarcal. Dentre essas ampliações, vislumbram-se alguns itinerários discursivos, a saber: a) na primeira parte do texto, é problematizado o papel do Estado na regulação da ordem da guerra, em suma, da violência; b) na sequência, é discutida a gênese da violência contra a mulher a partir da institucionalização do patriarcado; c) em um terceiro momento, é realizada uma breve retomada de questões centrais para a compressão da teoria feminista e sua história no seio de uma organização social fundamentada na relação de superioridade do masculino sobre o feminino; d) por fim, os argumentos que conduziram a discussão proposta são sintetizados e sistematizados a fim de mostrar como opera a ordem da guerra a partir da institucionalização das prerrogativas discursivas do patriarcado.

\section{O ESTADO E A ORDEM DA GUERRA}

O papel do Estado no contexto neoliberal passa por um processo de "desestatização" em sua forma/funcionalidade e em seus modos de estabelecer as tecnologias de governo (JESSOP, 2002). Com o advento do Estado mínimo, todo e qualquer resquício de proteção social do Estado de Bem-Estar Social, tipificação provedora em países de capitalismo avançado do pós-guerra, inscreve-se no âmbito de interdições.

Essa racionalidade discursiva engendra-se em modos específicos de gerenciamento da ordem da guerra, em que alguns modos de vida e existência devem ser destituídos e, se possível, eliminados; forja-se assim um agenciamento de constante exclusão social e violência. Para tal, no contexto latino-americano, em específico no Brasil, a violência tem sido o centro de discussões em diversos setores da sociedade, sobretudo devido à grave crise de governança do Estado brasileiro em razão do aumento da criminalidade, em especial a organizada, e da ineficácia de políticas públicas que revertam essa situação.

Quanto à ineficácia das políticas públicas por parte dos governos, também se faz necessário (re)pensá-las dentro de seus contextos de influência mais ampla, pois sob a racionalidade da governamentabilidade neoliberal, a sociedade civil é "convidada" a pensar, propor e responsabilizar-se pelo fracasso e/ou sucesso das políticas, em uma profusão das esferas pública/privada. Para Secchi (2009, p. 359), “[...] a etiqueta 'governance' denota pluralismo, no sentido de que diferentes atores têm, ou deveriam ter, o direito de influenciar a construção das políticas públicas”. 
E nesse ínterim de autonomia relativa, o Estado passa da condição moderna de provedor para "Pós-Estado" de regulação, já não partindo de si a responsabilidade moral e provedora sobre $\mathrm{o}$ atendimento das demandas sociais (saúde, educação, desenvolvimento social etc.). A sociedade civil e o mercado também passam a "assumir e gerir" tais demandas, em uma forma específica de governo dos vivos e aqui os desejos e paixões de grupos específicos entram em cena, podendo acirrar ainda mais a violência contra determinados grupos e demandas de maneira a operar modos específicos de poder:

Onde há poder, ele se exerce. Ninguém é, propriamente falando, seu titular; e, no entanto, ele sempre se exerce em determinada direção, com uns de um lado e outros do outro; não se sabe ao certo quem o detém; mas se sabe quem não o possui. (FOUCAULT, 2002, p. 137-138).

A relação de poder entre modos de governança e violência vem sendo tecida ao longo da história, operando e estruturando a sociedade, principalmente, no que diz respeito à desigualdade social refletida na assimetria de poder entre os gêneros sociais e suas ramificações. A noção de gênero social se molda à cultura e define-se como um construto sócio-histórico que determina as identidades e associa características biológicas a comportamentos e à aparência física (BUTLER, 2018). Além disso, é a noção de gênero que delibera a quem pertence a gerência da vida social. "Ao feminino, o mundo do sentimento, da intuição, da domesticidade, da inaptidão, do particular; ao masculino, a racionalidade, a praticidade, a gerência do universo e do universal" (SWAIN, 2001, p. 69). O gênero seria, portanto, uma interpretação cultural do sexo biológico.

A Assembleia Geral das Nações Unidas, em 20 de dezembro de 1993, apresentou a resolução 48/104, em que destacou que a violência de gênero é um dos mecanismos sociais cruciais pelos quais as mulheres são forçadas a uma posição de subordinação em relação aos homens. O documento define a violência contra a mulher ou violência de gênero como qualquer ato de violência de gênero que resulte ou possa resultar em danos ou sofrimento físico, sexual ou psicológico às mulheres, incluindo ameaças, coerção ou privação arbitrária da liberdade, ocorrendo na vida pública ou privada (UNITED NATIONS, 1993).

Pensando em uma problematização mais ampla é que se considera o processo de transição para o Estado Mínimo para além da “[...] necessidade de alterar suas funções para viabilizar o crescimento econômico interno e superar a crise que levava ao aumento da desigualdade e exclusões sociais" (BAUER, 2013, p. 8), o Estado passou a enfrentar outras reconfigurações na trama do tecido social, como Clarke e Newman (1997, p. 9-12) descrevem:

[...] o acordo social, formado na interseção de 'família, trabalho e nação', não provou ser mais estável do que sua contrapartida econômica e política. A interação de mudanças sociais - na composição de lares, trabalhadores e o povo - com novas formas de movimentos sociais, culturais e políticos desestabilizou profundamente o acordo social. Linhas específicas de diferenciação social tornaram-se um foco para ação coletiva e conflito político. Muitos destes estavam centrados em divisões que eram anteriormente tratadas como categorias naturais (como 'raça', gênero e sexualidade) nas quais a ação coletiva procurava redefini-las como socialmente produzidas e construídas. [...] estes desafios também colocam em questão a natureza da neutralidade do 
estado de bem-estar quando incorporada a seus regimes organizacionais profissionais de gabinete.... Ao invés de neutralidade, foi revelado que tanto as regras formais como informais das burocracias e práticas de profissionalismo contribuíam para a produção e reprodução de poder e desigualdade. A formação e a implementação de políticas, práticas de emprego e culturas organizacionais características de instituições de bem-estar estavam todas implicadas... a crise do social penetrou profundamente no mundo organizacional e ocupacional do 'antigo' estado de bem-estar.

Destaca-se, assim, a visibilidade para o gênero social feminino, uma vez que o direito positivo passou a atuar por meio das instituições de Estado (judiciário e escolas, por exemplo) como forma de inibir os efeitos da ordem da guerra. Em suma, a mulher passou a assumir espaços de saber, poder e legitimidade (jurídica e moral) na esfera pública. O Estado passou a "permitir" que a mulher investisse na sua escolarização - do acesso à verticalização - e consequentemente "permitiu" que a mesma "fugisse" da esfera privada do lar. Todavia, é corriqueiramente sabido que isso não a desvinculou das "obrigações do lar e da maternagem", pelo contrário, colocou-a em uma situação de "liberdade vigiada".

As conquistas do gênero social feminino tornam-se uma ameaça ao status quo da normatividade social, leia-se: sob bases masculinas, pois "como a mulher ousa a querer igualar-se em direitos com os homens? Inverter os valores de uma realidade "naturalmente" dada, fixa e essencial?". O histórico de dominação do gênero social masculino sobre o gênero social feminino é datado desde os primórdios da humanidade, mas, na contemporaneidade, os dados de violência contra as mulheres no Brasil têm assumido patamares demasiadamente alarmantes.

Observa-se um crescimento da violência contra a mulher de 7,3\% entre os anos de 2005 e 2015. Os números indicam que 4621 mulheres foram assassinadas no Brasil, o que corresponde a uma taxa de 4,5 mortes para cada 100 mil mulheres (CERQUEIRA; LIMA; BUENO; VALENCIA; HANASHIRO; MACHADO; LIMA, 2017, p. 38). No Rio Grande do Sul, no geral, as mortes na população feminina representam uma taxa de 40,5\% de homicídios, entre os anos de 2005 a 2015.

A violência de gênero pode ser considerada o resultado da distribuição desigual de bens e de serviços materiais e imateriais entre os gêneros sociais masculino e feminino. Os discursos e as práticas culturais do que é "ser homem" e do que é "ser mulher" gerenciam as relações interpessoais e é dessas relações que as expressões de poder emergem, e de onde ecoam a incapacidade de cumplicidade e de interação social saudáveis entre os universos masculino e feminino na contemporaneidade.

[...] mesmo quando os direitos lhe são abstratamente reconhecidos, um longo hábito impede que encontrem nos costumes sua expressão concreta. Economicamente, homens e mulheres constituem como que duas castas; em igualdade de condições, os primeiros têm situações mais vantajosas, salários mais altos, maiores possibilidades de êxito que suas concorrentes recém-chegadas. Ocupam na indústria, na política etc., maior número de lugares e os postos mais importantes. Além dos poderes concretos que possuem, revestem-se de um prestígio cuja tradição a educação da criança mantém: o presente envolve o passado e 
no passado toda a história foi feita pelos homens. (BEAUVOIR, 2019a, p. 17).

Então, quais pulsões de vida estão/seriam possíveis? Faz-se necessário recusar pura e simplesmente o Estado? Há caminhos possíveis, uma vez que o Estado gerencia o governo dos vivos? Nesse sentido, Foucault (1995) traça algumas pistas para pensar:

Talvez, o objetivo hoje em dia não seja descobrir o que somos, mas recusar o que somos. Temos que imaginar e construir o que poderíamos ser para nos livrarmos desse "duplo constrangimento" político, que é a simultânea individualização e totalização própria às estruturas de poder moderno. A conclusão seria que o problema político, ético social e filosófico de nossos dias não consiste em tentar liberar o indivíduo do Estado nem das instituições do Estado, porém nos liberarmos tanto do Estado quanto do tipo de individualização que a ele se liga. Temos que promover novas formas de subjetividade através da recusa deste tipo de individualidade que nos foi imposto há vários séculos (FOUCAULT, 1995, p. 239).

Além disso, o autor também provoca o pensamento para problematizar a relação entre liberdade e opressão, enfatizando que "a liberdade não começa ali onde cessa a intervenção centralizada do Estado (...). De fato, não creio que o poder seja somente o Estado, ou que o não-Estado já seja a liberdade" (FOUCAULT, 2002, p. 323).

Constituída essa problematização inicial - em cunho contextual - pode-se dizer que o fenômeno da violência contra a mulher ganha visibilidade em tantas outras esferas discursivas (classe social, gênero, raça, entre outras em devir de existência), mas está constantemente organizada pela transversalidade do patriarcado, uma discursividade com efeitos de conservação opressora contra a qual o feminismo se levanta.

\section{A INSTITUCIONALIZAÇÃO DO PATRIARCADO E O FEMINISMO COMO RESISTÊNCIA}

Segundo Aguiar (2000, p. 305), na "literatura feminista internacional, a discussão sobre o patriarcado tem indicado a existência desse fenômeno quando existe uma ausência de regulação da esfera privada em situações onde há um notável desequilíbrio de poder dentro dessa instância." Ainda, segundo o autor (2000), o patriarcado pode ser comparado ao escravismo. "Esse diagnóstico gera uma série de demandas normativas críticas de correção das situações de arbítrio de poder dentro do espaço familiar e para além do mesmo" (p. 305). O patriarcado, nessa perspectiva, define-se como um sistema de organização social sobre o qual se assentam todas as sociedades contemporâneas. Caracteriza-se por ser um modo de organização social "natural" e dado institucionalmente ao homem que detém poder sobre as mulheres, a vida social, a produção e o consumo, a política, a religião, a legislação e a cultura.

É essa estrutura social histórica e ideológica que determina o que é esperado, permitido e valorizado em uma mulher e o que é esperado, permitido e valorizado em um homem. Os papeis pré-estabelecidos nessa estrutura social têm um impacto específico sobre as mulheres e homens em todas as fases da vida e podem determinar diferenças na 
forma como bens e serviços materiais e imateriais, tais como acesso à saúde, à educação, ao trabalho, à vida familiar e ao bem-estar geral de cada um, são distribuídos. Observamse diferenças em relação às funções e às responsabilidades atribuídas aos homens e às mulheres como, por exemplo, acesso a carreiras profissionais, ao controle sobre os recursos, bem como oportunidades de tomada de decisão (SALAIBE, 2018. p. 17). As diferenças podem ser consideradas os mecanismos sociais em que se desenvolvem os estigmas sociais, os preconceitos e todos os tipos de discriminação. A discriminação pode ser considerada como um estado de espírito egocêntrico em que um indivíduo não sente empatia pelo outro pelo fato deste outro ser diferente de alguma forma. A estrutura social reduz os espaços de atuação da mulher na sociedade a partir da maternidade imposta e da sua "domesticidade" inerente (BEAUVOIR, 2019b). A mulher é designada para a maternidade: ficar em casa e cuidar dos filhos.

Historicamente, crenças e paradigmas padronizaram culturas que secundarizam o papel da mulher na sociedade e supervalorizam o papel do homem. A título de ilustração da supremacia masculina, a Filosofia e a Ciência usam o termo homem para designar a totalidade dos humanos: homens e mulheres, como seres opostos. A partir do olhar filosófico, estabeleceu-se como norma a prevalência de dominar ao ser homem e de obedecer ao ser mulher. Esse modelo gerado pelo pensamento de filósofos homens trata a mulher como um outro ser, depreciativo e rebaixado (SWAIN, 2001).

Durante muitos anos, a ciência tentou comprovar "a inferioridade da mulher", como o "sexo frágil", a partir de argumentos baseados em conceitos biológicos, tal como ilustra o livro A Mulher delinquente, a Prostituta e a mulher Normal, escrito no século XIX por Cesare Lombroso e Guglielmo Ferrero (CUNHA, 2019). Esse livro pode ser considerado um exemplo de discurso "científico" que busca sancionar, padronizar e regular o papel da mulher na sociedade. Os autores classificaram as mulheres que não se encaixam no padrão de domesticidade como delinquentes e degeneradas (CUNHA, 2019, p. 57). Conforme o determinismo biológico, a espécie humana apresenta indivíduos com sexos distintos, ou seja, possui machos e fêmeas, considerando-se unicamente o ponto de vista biológico, homens e mulheres. Isso caracteriza a presença de dois tipos distintos de indivíduos em uma espécie, atribuindo ao homem maior força física e capacidade mental (BEAUVOIR, 2019a).

A supremacia do sexo biológico masculino parece surgir da ideia de dominação que restringe as noções de mulher e feminino à inferioridade física, o que justificaria a necessidade de dominação. Esses elementos são traduzidos também por discursos que buscam atestar a incapacidade intelectual, dependência da aparência do corpo e de seu sexo. São modos de existência e atuação social que vêm sendo reafirmados em imagens e palavras que povoam o imaginário ocidental, destinando as mulheres a um lugar abaixo dos homens (SWAIN, 2001, p. 16).

A organização social é desigual porque responde às normas do sistema patriarcal, que mantém o poder primário e as funções de liderança política, autoridade moral, privilégios sociais e controle das propriedades na gerência do masculino. Esse sistema parece ser o andaime pelo qual se sustenta a violência contra a mulher: é nele que se respaldam discursos que atribuem à mulher a culpa pelos diversos tipos de violência sofridos. Por exemplo, quando abusada sexualmente, seria a mulher que induziria esse comportamento no homem, ao "insinuar-se" para ele. O que pode ser considerado 
contraditório na medida em que reduz o masculino a sua versão animalesca e, portanto, irracional. Em Bruxelas, na Bélgica, uma exposição de roupas de vítimas de estupro desconstruiu essa lógica. Os expositores mostraram que muitas vítimas vestiam calças e blusas discretas, pijamas e até camisetas largas quando sofreram a violência sexual (BBC, 2018).

Discursos pregados em diversos templos religiosos parecem estipular e estimular a submissão de fiéis a Deus. Para que haja a certeza de que a congregação ficará submissa às ordens da igreja, são criadas doutrinas que orientam o ser humano, podendo torná-lo ausente de autonomia para pensar e sintetizar conceitos diferentes dos estipulados pela igreja. Alguns discursos religiosos se alicerçam no patriarcado, que representa uma ordem social autoritária que enxerga a mulher como o outro sexo, inferior e submisso. A título de ilustração a "visão cristã negativa da corporeidade, devida à compreensão dualista tradicional que prioriza 'o espírito' (grifo da autora), acaba por atribuir às mulheres, responsáveis pela reprodução da espécie, um lugar não apenas secundário, mas de periculosidade" (ROSADO-NUNES, 2006, p. 296).

De modo semelhante, o discurso jurídico também apresenta, por vezes, traços que o alinham a uma postura patriarcal. Como exemplo a Lei de Alienação Parental ${ }^{4} \mathrm{n}^{\mathrm{o}}$ 12.318 , de 26 de agosto de 2010. Ferreira e Enweiler (2014, p. 95) apontam que essa lei pode forjar um álibi para homens agressores de mulheres e de crianças. Segundo os autores:

Entidades internacionais de defesa das mulheres e das crianças têm há muito alertado acerca da prática de preconceito de gênero (em geral contra as mulheres), evidenciado em casos envolvendo acusações de violência doméstica e alienação parental. Denunciam que as Cortes de Justiça (entre elas as norte-americanas), mesmo hoje, tendem a minimizar as acusações de violência sejam elas físicas, sexuais ou psicológicas em desfavor de mulheres e crianças, privilegiando pais e maridos agressores.

Os autores (2014) apontam também que a parcialidade, nesses casos, pode ser considerada uma ferramenta poderosa para desqualificar a credibilidade das mulheres que denunciam o abuso sexual de crianças. Assim como em outros discursos, a mulher, nos contextos citados, assume o papel de "bruxa". A esses dois exemplos relaciona-se, ainda, a misoginia que impulsiona a violência contra a mulher, que é discriminada e rebaixada ao domínio masculino pelos mecanismos de regulamentação do patriarcado, muitas vezes, tendo a sua voz e a legitimidade de seus direitos questionadas. A misoginia pode ser compreendia como a repulsa, o desprezo e o ódio contra as mulheres, e essa aversão ao feminino parece estar relacionada à violência que é praticada contra a mulher.

A Figura 1 (ZH/GAÚCHA) ilustra um caso de violência contra a mulher em que, mesmo com medida protetiva, o agressor comete o crime de feminicídio contra a excompanheira. Um professor da educação básica, em uma cidade do interior do Estado do

\footnotetext{
4 "Considera-se ato de alienação parental a interferência na formação psicológica da criança ou do adolescente promovida ou induzida por um dos genitores, pelos avós ou pelos que tenham a criança ou adolescente sob a sua autoridade, guarda ou vigilância para que repudie genitor ou que cause prejuízo ao estabelecimento ou à manutenção de vínculos com este". (BRASIL, 2010).
} 
Rio Grande do Sul - onde este estudo se desenvolveu -, de 49 anos assassinou sua esposa e, na sequência, suicidou-se, no dia vinte sete de abril de 2017.

Figura 1. Caso de feminicídio (GAÚCHA, ZH, 2018).

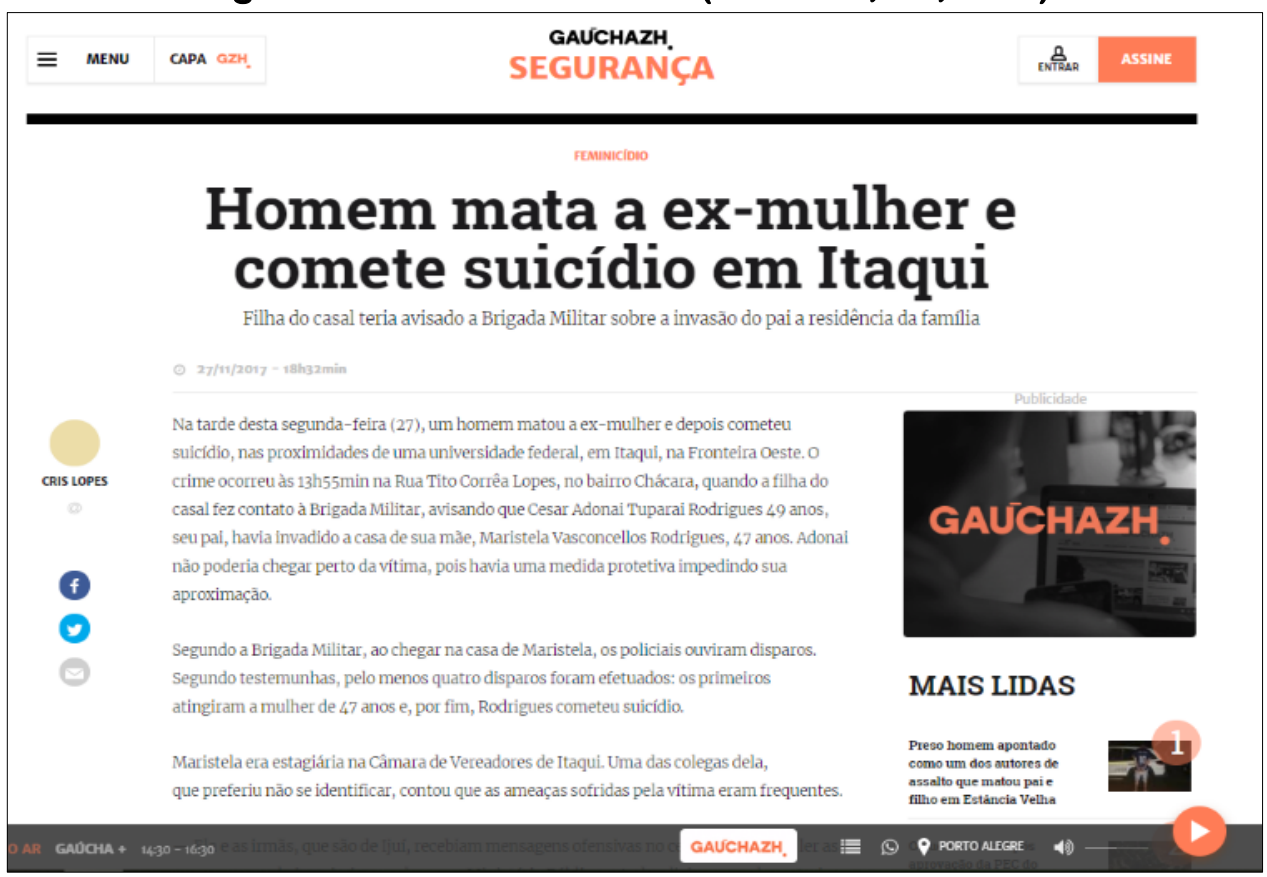

Em contraponto à violência contra a mulher, Meneghel e Hirakata (2011, p. 555556), apontam que "os assassinatos masculinos não ocorrem pela desigualdade de gênero, e sim por conflitos que ocorrem no espaço da rua: brigas, controle do território, pertencimento a gangues, narcotráfico, grupos de extermínio". Por outro lado, as mortes de mulheres estão, como demonstram os dados do Atlas da violência (IPEA, 2017), atreladas às relações de poder assimétricas entre os universos masculino e feminino validados por valores e crenças culturais.

Prevalece culturalmente a ideia de que a mulher está biologicamente mais próxima da natureza, enquanto o homem está intelectualmente mais próximo da cultura. Uma vez que a cultura seja vista como superior à natureza em sociedades como a nossa foi dada ao homem uma posição social superior à da mulher. As mulheres são vistas, por vezes, apenas em virtude das suas propriedades biológicas de menstruação, de gravidez, de procriação e de amamentação. Daí restringiu-se o papel da mulher à criação dos filhos no lar - ou seja, ao mundo doméstico - enquanto que as atividades externas e intelectuais caberiam ao homem, o qual não está sujeito a tais funções biológicas, portanto, apropriado para as atividades externas do lar (SWAIN, 2001).

Novamente o exemplo do discurso religioso que, muitas vezes, construiu a sua narrativa inferiorizando o papel da mulher na sociedade e ditou as formas de interação social. Imperadores, ao longo da história, sofreram a influência de líderes políticos de modo mitigado. Para muitos autores, o mito de que o feminismo é subversivo surge na crença de que ampliar o papel social da mulher e sua liberdade, retirando-a de sua natural inferiorização destruiria as intuições familiares e escravizaria o homem. 
[...] O mito de que as feministas eram «monstros antinaturais» (grifo da autora) baseava-se na crença de que destruir a submissão da mulher, ordenada por Deus, seria destruir o lar e escravizar os homens. Tais mitos surgem em todas as revoluções que fazem progredir uma parcela da família humana no sentido da igualdade. Sejam as feministas representadas como seres desumanos, furiosas devoradoras de homens, ofensoras de Deus, ou nos termos modernos como pervertidas sexuais, não diferem nisso do estereótipo do membro de sindicato anarquista, ou do negro encarado como animal primitivo. O que a terminologia sexual oculta é o fato de que o movimento feminista era uma revolução. (FRIDMAN, 1971, p. 77).

A título de ilustração, a legislação de Justiniano honrava a mulher como esposa e mãe, mas escravizava-as a essas funções; não é de seu sexo, mas sim de sua situação no seio da família que decorreria sua incapacidade social (BEAUVOIR, 2019a).

Todos afirmavam que seu papel era procurar realizar-se como esposa e mãe. A voz da tradição e da sofisticação freudiana diziam que não podia desejar melhor destino do que viver a sua feminilidade. Especialistas ensinavam-lhe a agarrar seu homem e a conservá-lo, a amamentar os filhos e orientá-los no controle de suas necessidades fisiológicas, a resolver problemas de rivalidade e rebeldia adolescente; a comprar uma máquina de lavar pratos, fazer pão, preparar receitas requintadas e construir uma piscina com as próprias mãos; a vestir-se, parecer e agir de modo mais feminino e a tornar seu casamento uma aventura emocionante; a impedir o marido de morrer jovem e aos filhos de se transformarem em delinqüentes. (FRIDMAN, 1971, p. 17).

No âmbito da família, o pai ou a figura paterna tem a autoridade sobre a família. Ele recebe reforço institucional, e os relacionamentos interpessoais são marcados pela dominação e violência de um gênero social sobre o outro, o que tem sido questionado no campo de estudos feministas.

O movimento feminista tem importante função no combate à violência de gênero; e o tema da violência contra a mulher se tornou o eixo pelo qual se desenvolvem as discussões no campo de estudos feministas e do movimento feminista. O feminismo surgiu após a Revolução francesa e se fortaleceu na Inglaterra, durante o século XIX, e depois nos Estados Unidos, no começo do século XX. Esse movimento lutava, inicialmente, pela igualdade de condições entre homens e mulheres no sentido de que ambos tivessem os mesmos direitos e as mesmas oportunidades de acesso à educação, ao trabalho e ao bem-estar social geral.

Os movimentos feministas foram iniciados por mulheres que se rebelaram contra a condição de vulnerabilidade social a qual estavam submetidas e lutaram por liberdade e direitos até então exclusivos aos homens. $\mathrm{O}$ feminismo surge não somente como uma alternativa, mas como um mecanismo para trazer à discussão a questão da mulher, sua posição e sua condição na sociedade (PINTO, 2010, p. 1), sobretudo em relação à crescente desvalorização da vida da mulher.

O patriarcado acentua a desigualdade de gênero e gerou um vasto histórico de violência contra a mulher. Segundo Simone de Beauvoir (2019b), a história mostra que 
os homens sempre detiveram todos os poderes e a gerência da sociedade. Eles, os homens, entenderam ser útil manter a mulher em condição de subalternidade, o "outro" - nos termos da crítica da filósofa - que precisa de um representante em função da sua condição de inferioridade. "A humanidade é masculina, e o homem define a mulher não em si, mas relativamente a ele; ela não é considerada um ser autônomo" (BEAUVOIR, 2019a, p. 12).

A situação de vulnerabilidade feminina é resultado da sua definição como o “outro" (BEAUVOIR, 2019a, p. 27). É nesse contexto de restrição à liberdade feminina que o feminismo surge como um movimento social depois como uma teoria (PINTO, 2010) e, principalmente, como uma tentativa de trazer à discussão a violência gerada por um sistema social e cultural que dá ao homem adulto poderes sobre a mulher.

A partir disso, proteger todos aqueles que estejam/sejam alocados no âmbito do universo feminino é um dos propósitos do feminismo. É um movimento científico e político que problematiza e questiona o papel historicamente atribuído às mulheres visando a uma mudança na perspectiva social. Segundo Matuella (2017, p. 1279), a "principal preocupação para a teoria feminista é explicar a subordinação das mulheres e a assimetria entre homens e mulheres nas posições sociais, econômicas e políticas, e, assim, encontrar soluções para essa problemática".

É importante pontuar que feminismo não equivale e nem se opõe ao machismo, o qual pode ser compreendido como uma construção social e cultural que justifica atos de agressão e opressão contra as mulheres, além de sugerir a superioridade masculina. Por outro lado, o feminismo é um movimento científico, político e social que luta contra as manifestações do machismo na sociedade. Assim, o objetivo final do feminismo é construir uma sociedade que ofereça igualdade de condições entre os universos feminino e masculino (PINTO, 2010. p. 8).

Para Pinto (2003, 2010), há três fases ou momentos do feminismo, o que permite verificar-se assim três objetivos na constituição histórica do feminismo. Na primeira fase, o objetivo foi assegurar os direitos básicos civis das mulheres. Isso aconteceu no final do século XIX e foi até o início do XX, as Sufragetes, operárias inglesas, promoveram grandes manifestações a fim de adquirir o direito ao voto e à cidadania (PINTO, 2010, p. 15). Na segunda fase, as mulheres buscaram conquistar leis que garantissem a sua cidadania e individualidade. Essa fase é sobre manter seus direitos valendo e fazer todo o mundo entender que eles existem. Por fim, a terceira fase, a atual, é a do "sexo", é o momento histórico em que a mulher começa a vislumbrar seu corpo de outra forma, depois de um longo período quando ela foi levada a acreditar que seu corpo era apenas para o prazer do seu parceiro.

Essa onda pode ser considerada aquela que talvez tenha questionado de forma mais pulsante os paradigmas sociais, visto que objetivou problematizar as relações assimétricas entre os universos masculino e feminino, o que gera certo desconforto porque questiona privilégios do masculino, resultando no aumento dos índices de violência contra a mulher (PINTO, 2010). 


\section{CONSIDERAÇÕES FINAIS: A GÊNESE E A REPRODUÇÃO DA VIOLÊNCIA CONTRA A MULHER}

Este artigo teve como objetivo expor aspectos da ordem da guerra que abrangem a violência contra a mulher a partir da tentativa de estabelecer um cotejo com elementos da organização social que parecem alicerçar a ideologia do patriarcado. Por meio de um levantamento e um mapeamento bibliográfico, identificou-se que a imagem imposta às mulheres as coloca em situação de vulnerabilidade histórica, social, econômica e política. Essa vulnerabilidade foi construída a partir do modo como bens e serviços materiais ou imateriais são distribuídos e acessados na/pela sociedade e a maneira como são percebidos por instituições sociais tais como a religiosa, a jurídica e a científica.

O feminismo surge como movimento social e científico problematizador dessa forma de organização social e, ao longo de sua história, tem se reinventando de modo a desvendar e desnaturalizar aspectos da cultura e da estrutura social que surgem a cada dia como mecanismos para coibir a ampliação da liberdade de existência e escolha feminina na sociedade. No momento atual, o feminismo, enquanto movimento político e teoria científica, centra seus esforços em problematizar o modo como as relações de poder entre os gêneros sociais, com base no sexismo, são fundamentadas na cultura. Observam-se esforços para mudar o modo como as instituições veem a mulher, em especial, a midiática e a educacional. Surgiram conceitos como "nova masculinidade" e "masculinidade tóxica" para conseguir dar conta dos novos papéis sociais atribuídos aos homens e ao aumento da aversão a qualquer ampliação ou mudança nos direitos e deveres da mulher.

Supõe-se, por fim, que o aumento dos índices de violência contra o corpo social feminino seja uma resposta social a esses questionamentos e tentativas de aumento do espaço de atuação da mulher na sociedade, no geral, e nas instituições como um todo. Embora seja possível perceber as conquistas alcançadas, há ainda um longo caminho a ser percorrido para sanar os diversos tipos de preconceitos e discriminações associados à figura da mulher. A aversão à ampliação dos direitos e deveres das mulheres na contemporaneidade relaciona-se ao que Simone de Beauvoir (1970) argumentava: basta uma crise política, econômica e social para que os direitos das mulheres sejam questionados.

\section{REFERÊNCIAS}

AGUIAR, Neuma. Patriarcado, sociedade e patrimonialismo. SOCIEDADE E ESTADO, Universidade Federal de Brasília, Brasília, p. 303-330, 2000. Disponível em $\quad<$ https://www.scielo.br/scielo.php?script=sci arttext\&pid=S010269922000000200006\&lng=en\&nrm=iso $>$; acesso em 16 de set. 2020.

BRASIL. Lei 12.318, de 26 de agosto de 2010. Dispõe sobre a alienação parental e altera o art. 236 da Lei ${ }^{\circ}$ 8.069, de julho de 1990. Diário Oficial da União, Brasília, DF. Disponível em $\quad<$ http://www.planalto.gov.br/ccivil_03/_Ato20072010/2010/Lei/L12318.htm>; acesso em 7 de mar. 2020.

BBC NEWS BRASIL. Exposição na Bélgica traz roupas de vítimas de estupro para romper mito de culpa da mulher. Disponível em < https://www.bbc.com/portuguese/geral-42643532. Brasil; acesso em 12 de nov. 2018. 
BAUER, Adriana. Avaliação e desempenho de professores: pressupostos e abordagens. Em: GATTI, Bernadete A. (Org.). O trabalho docente: avaliação, valorização, controvérsias. Campinas, SP: Autores Associados; São Paulo: Fundação Carlos Chagas, 2013. pp. 5-70.

BEAUVOIR, Simone. O segundo sexo: fatos e mitos. 5. ed. Rio de Janeiro: Nova Fronteira, 2019a.

BEAUVOIR, Simone. O segundo sexo: a experiência vivida. 5. ed. Rio de Janeiro: Nova Fronteira, 2019b.

BUTLER, Judith. Problemas de gênero: feminismo e subversão da identidade. $16^{\mathrm{a}}$ ed. Rio de Janeiro: Civilização brasileira, 2018.

CERQUEIRA, Daniel; LIMA, Renato Sérgio; BUENO, Samira; VALENCIA, Luiz Iván; HANASHIRO, Olaya; MACHADO, Pedro Henrique; LIMA, Adriana dos santos. Atlas da violência. Rio de Janeiro: Fórum Brasileiro de Segurança Pública/IPA, 2017. Disponível em

https://www.ipea.gov.br/portal/images/170602_atlas_da_violencia_2017.pdf $>$; acesso em 03 mar. 2020.

CUNHA, Bárbara Madruga da. Uma análise histórica da criminalização do auto aborto no Brasil (1890-1940): dos discursos médicos ao positivismo criminológico. EM PERSPECTIVA, Universidade Federal do Ceará, Ceará, p. 49-71, 2018. Disponível em $<$ http://www.periodicos.ufc.br/emperspectiva/article/view/41523>; acesso em 13 set. 2020.

CLARKE, John; NEWMAN, Jane. The Right to Manage: a second managerial revolution? CULTURAL STUDIES, University of Birmingham, Londres, Routledge, $p$. 427-441, 1997.

FOUCAULT, Michel. O sujeito e o poder. Em: Paul, RABINOW e Hubert, DREYFUS. Michel Foucault: uma trajetória filosófica para além do estruturalismo e da hermenêutica. Rio de Janeiro: Forense Universitária, 1995. pp. 229-249.

FRIEDAN, Betty. Mística Feminina. Rio de Janeiro: Vozes limitada, 1971.

JESSOP, Bob. The future of the capitalist state. Cambridge: Polity, 2002.

KATZ, Chaim Samuel. FOUCAULT, Michel. Problematização do sujeito. REVISTA

LATINOAMERICANA DE PSICOPATOLOGIA FUNDAMENTAL, Associação Universitária de Pesquisa em Psicopatologia Fundamental, São Paulo, p. 183-188, 2000. Disponível em http://www.scielo.br/scielo.php?script=sci arttext\&pid=S1415$47142000000100183 \& \operatorname{lng}=$ en\&nrm=iso; acesso em 16 de set. 2020.

LOPES, Cris. Homem mata a ex-mulher e comete suicídio em Itaqui, GZH segurança. Disponível em https://gauchazh.clicrbs.com.br/seguranca/noticia/2017/11/homem-mataa-ex-mulher-e-comete-suicidio-em-itaqui-cjaineqm70fll01np970hzt0d.html; acesso em 12 de dez. 2018.

MATUELLA, Iazana. Conflitos armados e a agenda internacional: a questão da mulher. REVISTA DE ESTUDOS FEMINISTAS, Universidade Federal de Santa Catarina, Florianópolis, p. 1277-1295, 2017. Disponível em http://www.scielo.br/scielo.php?script=sci arttext\&pid=S0104026X2017000301277\&lng=en\&nrm=iso; acesso em 16 de set. 2020.

MENEGHEL, Stela Nazareth; HIRAKATA, Vania Naomi. Femicídios: homicídios femininos no Brasil. REVISTA DE SAÚDE PÚBLICA, Faculdade de Saúde Pública da Universidade de São Paulo, São Paulo, p. 564-574, 2011. Disponível em: http://www.scielo.br/scielo.php?script=sci arttext\&pid=S0034-

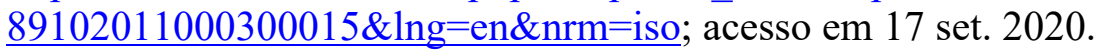


PINTO, Célia Regina Jardim. Feminismo, história e poder. REVISTA DE SOCIOLOGIA POLÍTICA, Universidade Federal do Paraná, Curitiba, p. 15-23, 2010. Disponível em http://www.scielo.br/scielo.php?script=sci arttext\&pid=S0104$44782010000200003 \& \operatorname{lng}=$ en \&nrm=iso; ; acesso em 16 de set. 2020.

ROSADO-NUNES, Maria José. Teologia feminista e a crítica da razão religiosa patriarcal: entrevista com Ivone Gebara. REVISTA DE ESTUDOS FEMINISTAS, Universidade Federal de Santa Catarina, Florianópolis, p. 294-304, 2006. Disponível em $<$ https://www.scielo.br/scielo.php?script=sci arttext\&pid=S0104-

026X2006000100016>; acesso em 16 de set. 2020.

SALAIBE, Vanessa Motta. Análise da violência contra a mulher no município de Itaqui/RS. Trabalho de Conclusão de Curso. Curso de Bacharelado Interdisciplinar em Ciência e Tecnologia, Universidade Federal do Pampa, Itaqui, RS, 2018.

SECCHI, Leonardo. Modelos organizacionais e reformas da administração pública. REVISTA DE ADMINISTRAÇÃO PÚBLICA. Fundação Getúlio Vargas, Rio de Janeiro, p. 347-369, 2009. Disponível em < https://www.scielo.br/scielo.php?pid=S0034-

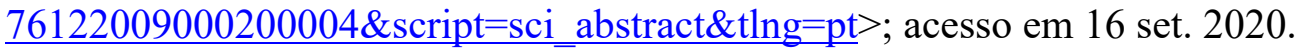

SWAIN, Tania Navarro. Feminismo e recortes do tempo presente: mulheres em revistas “femininas". SÃO PAULO EM PERSPECTIVA. Fundação SEADE, São Paulo, p. 6781, 2001. Disponível em $<$ https://www.scielo.br/scielo.php?pid=S0102$88392001000300010 \&$ script $=$ sci_abstract $>$; acesso em 02 de abr. 2020.

UNITED NATIONS. General Assembly Revolution n. 48/104 of 20 December 1993. Declaration on the elimination of violence against women. Geneva: Office of the United Nation High Commissioner for Human Rights, 1993. Disponível em $<$ https://www.ohchr.org/EN/ProfessionalInterest/Pages/ViolenceAgainstWomen.aspx $>$; acesso em jan. 2020.

Artigo recebido em: mai. de 2020.

Aprovado e revisado em: out. de 2020.

Publicado em: dez. de 2020.

Para citar este texto:

LOVATO, Cristina dos Santos; KEHLER, Gabriel dos Santos; MOTTA, Vanessa Salaibe. Dimensões Sócio-Históricas da Violência contra a Mulher: em pauta, a ordem da guerra. Entremeios [Revista de Estudos do Discurso, ISSN 2179-3514, on-line, www.entremeios.inf.br], Seção Estudos, Programa de Pós-Graduação em Ciências da Linguagem (PPGCL), Universidade do Vale do Sapucaí (UNIVÁS), Pouso Alegre (MG), vol. 22, p. 57-69, jul. - dez. 2020.

DOI: http://dx.doi.org/10.20337/ISSN2179-3514revistaENTREMEIOSvol22pagina57a69 